\title{
ARM or FRM: Which Mortgage Contract Is Better for Czech Households?
}

\author{
Ivan Rybár*, Petr Zemčík $k^{\dagger \ddagger}$ \\ CERGE-EI, \\ Charles University
}

June 2007

\begin{abstract}
Household housing decisions are usually taken early in life and therefore have significant welfare consequences. There are two types of loans available for households: fixed-rate mortgage (FRM) contracts and adjustable-rate mortgage (ARM) contracts. We investigate the welfare effects of fixed-rate and adjustable-rate mortgage contracts on Czech households by calibrating and solving a life-cycle model used for this purpose by Campbell and Cocco (2003). We compare the distribution of utility in simulations under FRM and ARM and find that FRM is preferred to ARM. This result is in conflict with findings that Campbell and Cocco (2003) report for U.S. households, probably due to higher inflation and real interest rate uncertainty in the Czech Republic.
\end{abstract}

JEL CLASSIFICATION: G12

KEY WORDS: household finance, housing, mortgage.

\footnotetext{
*I am grateful to Rastislav Seč for helpful comments and suggestions.

${ }^{\dagger}$ The second author would like to acknowledge support from the Marie Curie International Reintegration Grant \# 014864.

${ }^{\ddagger}$ For correspondence contact Petr Zemčík, Assistant Professor, CERGE-EI, Charles University, Politických věznu 7, 11121 Prague, Czech Republic, Tel: +420 224005 154, E-mail: petr.zemcik@cerge-ei.cz.
} 


\section{Introduction}

Decisions that households have to make in today's society, which shifts responsibility for the future into citizens' hands, have large welfare consequences. Whether we consider saving and investing or borrowing and spending, households have decisions to make that will influence their welfare for many years. The importance of research on the financial decisions of households has been stressed by Campbell (2006).

To study household decisions that have welfare implications that vary and last over the whole lifetime, economists are increasingly using life-cycle models, which were created to address precisely this kind of question. Examples of research that employs a lifecycle model are Gourinchas and Parker (2002), who study consumption, or Gomes and Michaelides (2005), who concentrate on household portfolios.

Economists agree that a house is the single most important asset in the portfolio of most households. Housing decisions are influenced by high adjustment costs, expected increases in labor income, increases in family size and other life-cycle considerations. Mortgages are usually taken early in life and influence household utility over the household's whole lifetime.

Because of the importance of housing in household finance, it has become an explicit part of asset pricing models since 1990's. Flavin and Yamashita (1998) formulate a consumption-based capital asset pricing model with the utility function being explicitly dependent both on the consumption of nondurable and durable goods (i.e., a house). Lifecycle models with risky labor income have been used to study the effects of income shocks on housing prices (Ortalo-Magne and Rady 2003) and portfolio choices in the presence of housing (Campbell and Cocco 2003, Cocco 2005). The impact of housing wealth on consumption expenditures is discussed by Case, Quigley, and Shiller (2001), for instance. The decision between renting and owning housing has been studied by Yao and Zhang (2005). Recently, Piazzesi, Schneider, and Tuzel (2007) explicitly model housing as both an asset and a consumption good. 
A convenient framework for an analysis of mortgage contracts is given in Campbell and Cocco (2003), who use a realistically and quantitatively calibrated life-cycle model with a finitely-lived household and risky labor income. The house prices enter the model via mortgage contracts and other aspects of the household portfolio choice are suppressed by assuming that household savings are used to buy a risk-less asset. Real estate prices matter in their model, since households can obtain a second one-period loan once they pay off a portion of their mortgage debt.

We calibrate this life-cycle model to the conditions prevailing in the Czech economy. We change many parameters of the model in order to reflect the Czech specifics of the term structure of interest rates, labor income risk, taxation and house prices, and other aspects of the model.

An important step of calibration is the estimation of the labor income profile for Czech households. We use an unbalanced panel of Czech households to estimate labor income for working age male heads of household, controlling for education, household size, and marriage. In the next step, we decompose the variance of residuals from this estimation to obtain the variance of shocks to the labor income process. Once the model is calibrated, it can be easily used to compare the welfare consequences of the mortgage choices of Czech households.

While mortgages are a well established form of financing housing in the U.S., mortgage contracts were not available to Czech households thirteen years ago (Hrdlicka 1998). The Czech mortgage market has evolved rapidly since that, however, and Czech banks now offer a wide selection of mortgage loans. However, it takes some time for innovative mortgages to become commonplace. We simplify the range of contracts available and compare a contract with a one-year adjustable interest rate (ARM) against a contract with a fixed interest rate (FRM). An additional difference between the U.S. and the Czech Republic is that we have relatively few data observations to estimate inflation and interest rate processes. 
In this study, we investigate the welfare consequences of these mortgage contracts. Specifically, we explore whether households are better under an ARM or a FRM contract. To study the difference in household welfare under ARM and FRM contracts, we calibrate to the Czech economy and numerically solve a model that closely follows Campbell and Cocco (2003). We find that contrary to the U.S., FRM is preferred to ARM for most households.

The paper is organized as follows: In Section 2 we present the model. Then, we comment on our data sources in Section 3. Section 4 contains a detailed explanation of the calibration of the model. Next, we briefly describe the solution method in Section 5 . Section 6 presents the results of our study and Section 7 concludes.

\section{Model}

\section{$2.1 \quad$ Preferences}

The lifetime of a household in our model is $\mathrm{T}$ periods. The household maximizes its lifetime utility by choosing consumption. The utility function is separable between nondurable consumption and housing. As we assume fixed house size, however, we can omit housing from the objective function. The agent chooses consumption in each period to maximize:

$$
E_{0} \sum_{t=0}^{T} \beta^{t} \frac{C_{t}^{1-\gamma}}{1-\gamma}+\beta^{T+1} \frac{W_{T+1}^{1-\gamma}}{1-\gamma}
$$

where $\mathrm{C}$ stands for non-durable consumption, $\mathrm{W}$ for end period wealth, $\gamma$ is the riskaversion parameter, and $\beta$ the discount factor.

\subsection{Labor Income}

To finance consumption and housing, the household offers labor in exchange for income. We do not model labor supply, and assume that labor income is a function of observable characteristics and a stochastic error term. These observable characteristics include 
education, age, marital status, and number of dependents. The labor income is exactly specified as follows:

$$
\log \left(\text { real_income }_{i, t}\right)=f\left(t, Z_{i, t}\right)+\nu_{i, t}+\epsilon_{i, t} .
$$

Note that $f\left(t, Z_{i, t}\right)$ stands for the deterministic part of the labor income process, which depends on age and other observable characteristics. $\epsilon_{i, t}$ is an idiosyncratic normally

distributed income shock with zero mean and variance $\sigma_{\epsilon}^{2} . \nu_{i, t}$ is a random walk process, defined as $\nu_{i, t}=\nu_{i, t-1}+u_{i, t}$, where $u_{i, t}$ is normally distributed with zero mean and variance $\sigma_{u}^{2}$

\subsection{Inflation}

Following Campbell and Cocco (2002), we model expected inflation as a first-order autoregressive process:

$$
\pi_{1, t}=\mu(1-\phi)+\phi \pi_{1, t-1}+e_{t}
$$

where $e_{t}$ is distributed normally with zero mean and variance $\sigma_{e}^{2}$.

\subsection{Interest Rates}

We model the real interest rate as follows:

$$
\log \left(1+R_{t}\right)=\bar{r}+\psi_{t}
$$

where $\bar{r}$ is the mean log real interest rate and $\psi_{t}$ is a normally distributed random variable with mean zero and variance $\sigma_{\psi}^{2}$.

The nominal interest rate is computed as follows: 


$$
\log \left(1+Y_{1 t}\right)=r_{1 t}+\pi_{t}+\zeta .
$$

To compute annuities, we need to specify long-term bond yields. A log yield on a n-period nominal bond can be expressed as:

$$
\log \left(1+Y_{n t}\right)=\frac{1}{n} \sum_{i=0}^{n-1} E_{t}\left[y_{1, t+i}\right] .
$$

We further assume that the realized log real return on a one-period bond equals expected real interest rate.

The interest rate on a FRM contract in date t follows

$$
Y_{T-t+1, t}^{F}=Y_{T-t+1, t}+\theta^{F},
$$

where $\theta^{F}$ is a mortgage premium on FRMs. Similarly, a nominal interest rate on an ARM contract is determined according to the following formula:

$$
Y_{1, t}^{A}=Y_{1, t}+\theta^{A} .
$$

$\theta^{A}$ is a mortgage premium on ARMs, and can be thought of as risk of default. Then, $\theta^{F}$ can be interpreted as the sum of risk of default and the value of the option to refinance the mortgage at a fixed cost.

\subsection{Taxation}

Labor income is taxed using a simple linear taxation rule $\tau$. 


\subsection{House Prices}

House prices grow in time according to the following formula:

$$
\Delta p_{t}^{H}=\frac{P_{t}}{P_{t-1}}=g+\delta_{t},
$$

where $\delta_{t}$ is a normally distributed random variable with mean zero and variance $\sigma_{\delta}^{2}$.

Additionally, we assume that house price shocks are positively correlated with permanent shocks to the household's labor income, that is,

$$
\delta_{t}=\alpha \eta_{t}
$$

where $\alpha>0$.

Note also that we assume fixed house size $\bar{H}$ and down payment ratio $\lambda$.

\subsection{Mortgage Contracts}

The per-period payment a household must make on its house under a FRM contract is determined as follows:

$$
M_{t}^{F}=\frac{(1-\lambda) P_{1}^{H} \bar{H}}{P_{t} \sum_{j=1}^{T}\left(1+Y_{T, 1}^{F}\right)^{-j}} .
$$

On the other hand, an ARM contract results in these per-period payments:

$$
M_{t}^{A}=\frac{Y_{1, t}^{A} D_{t}+\Delta D_{t+1}}{P_{t}}
$$

where $\Delta D_{t+1}$ is period t average nominal loan reduction in a FRM with identical initial loan size.

We do not allow households to finance consumption by increasing the size of their mortgage when their housing equity increases. 


\section{Data}

Our data on Czech households come from the Statistics of Family Accounts of the Czech Statistical Office. The Statistics of Family Accounts provides information on the structure of expenses of Czech households. When interpreting this data, it is important to bear in mind that the survey is done on a non-random sample of 3000 households. Note that the population of the Czech Republic is slightly above 10 million. Households included in the sample were chosen by stratified sampling, which limits the possibility of making inferences about the whole population. Nevertheless, the stratification procedure was made to closely resemble important distribution aspects. Therefore we use the sample as a representative sample of Czech households.

The sample is changed every year in such a way that it constantly mirrors the shifts in the basic attributes of households (their composition, economic activity, income level, etc.). Quotas determine how many households in each category must be included. The criteria include education, net monetary income, home ownership, and residence in village/town/city. Households stay in the sample for a whole year until their key characteristics change (that is, the economic activity of the household head, the income level for households with minimum income, etc.) The structure of the sample was designed to match the structure of data that are the results of the Microcensus (random sampling, with an aim to get representative data on the level and structure of income and basic demographic data), the size of the village/town/city and a home ownership dummy. The Income Profile is adjusted yearly according to the development of income.

The reporting unit is the household, that is, a group of people who live together and share basic expenses (food, utilities etc.). The core of the household is usually a family, but it could be an individual as well. The definition of a household is consistent with the definition recommended by Eurostat.

Primary data on income, expenses, and consumption come from households' daily notes. A representative of the Czech Statistical Office asks the household questions about 
the members, the house or condominium, family business and equipment owned.

Detailed information about the dataset can be found on the website of the Czech Statistical Office.

\section{Calibration}

\subsection{Labor Income Profile}

Our estimation of the labor income profile is part of calibration of an intertemporal lifecycle portfolio choice model. We need to calibrate our life-cycle model so that it matches the labor income profile.

From the original 48,498 observations, we eliminate female-headed, retiree, and oversampled low-income households from the sample, following Cocco, Gomes and Miachelides (2002) (CGM). We also eliminate households with a head of the household older than 60 or younger than 20 years old. After all these eliminations, we are left with 25,366 observations on 11,436 households. That is, a household stays in the panel for slightly more than two years, on average.

We define labor income broadly, including welfare benefits, social security payments, retirement income, income from farming, and help from relatives.

The next step is the creation of control variables for the regression. First, we create a variable for the household composition. Following CGM, the household composition equals the number of persons in households minus one for households, whose head is single and members less two for married household heads. We considered households that include an unmarried couple as with a married head of household, other household types as single head of household. Then we created a dummy indicating whether the head of household has completed high school or at least started college. Campbell and Cocco (2003) include dummies for the head of household's education, while CGM do not control for education in the regression. Instead, they run separate regressions for each educational group. We follow Campbell and Cocco (2003), who use a single regression for 
simplicity. We created one set of dummies for age, in 5-year intervals, the baseline being the 20-25 age bracket. We also need a variable for the number of additional persons in the household.

The last step before estimation is to deflate the labor income by the CPI. We have obtained the data on the CPI from OECD statistics. The series is provided in constant year 2000 prices.

We closely follow Campbell and Cocco (2003) and estimate equation (2) using the following fixed household effects regression on an unbalanced panel of Czech households stretching from 1991 to 2005 . We control for age, education, martial status, and household composition. We report the summary statistics in Table 1 . We report the results of both specified regressions of labor income on explanatory variables in Table 2.

For the estimated values of coefficients in the model without trend, we compute the expected logarithm of the income of a married, college-educated head of household with two children for each age bracket. We plot this expected logarithm of labor income against age for all age brackets, connecting the points using a fifth-degree polynomial. We report this result in Figure 1. Additionally, we report the estimated coefficients for fitting the polynomials of degrees two to five in Table 3.

We save the residuals from the regression above and compute, for each family and each year, from the 1-st up to the 14-th difference of residuals. These 14 columns of differences plugged into the above specified formula for variances of shocks to the labor income process give 14 equations in 2 unknowns. We solve this system to obtain efficient estimates of the variances of shocks and report the results in Table 4. Additionally, we report estimates based on just 5 and 2 equations in 2 unknowns. Our estimate of the temporary shock $\epsilon$ is unchanged in these different specifications. The permanent $\mathrm{u}$ shock, however, increases with the number of equations we include in the model. The solutions with 14 equations are efficient as they use all the information available to estimate the variances. However, including differences up to the 5-th order seems to be most appropriate, as very little 
observations are available for higher differences.

We closely follow Campbell and Cocco (2003) and estimate the above equation using a fixed effects regression. Afterwards, we estimate the error structure of the labor income process. We decomposed the variance of labor income process by applying the approach first used by Carroll and Samwick (1997). We define $r_{i t d} \equiv \log \left(Y_{i, t+d}^{*}\right)-\log \left(Y_{i t}^{*}\right), d \in$ $1,2, \ldots, 14$, where

$$
\log \left(Y_{i t}^{*}\right) \equiv \log \left(Y_{i t}\right)-\hat{f}\left(t, Z_{i t}\right)
$$

As a result,

$$
\operatorname{Var}\left(r_{i t d}\right)=d \sigma_{u}^{2}+2 \sigma_{\epsilon}^{2}, d \in 1,2, \ldots, 14
$$

We combine all possible series of $r_{i d}$ to get efficient estimates of $\sigma_{u}^{2}$ and $\sigma_{\epsilon}^{2}$. After that, we use the estimated variances and predicted deterministic part of labor income to generate 95\% confidence intervals for the labor income - age profile we have generated. We report the results in Figure 2.

\subsection{Interest Rate}

We also need to calibrate the real interest rate. We average the logarithms of gross returns determined by the Prague Interbank Offered Rates (PRIBOR) over 2000-2006 to get $3.43 \%$. The estimated standard deviation is 1.3098 . We would like to use the shortterm debt of the Czech government instead, but these data are not available. Hence we use PRIBOR as a proxy. 


\subsection{Mortgage premium}

The mortgage premium on FRM contracts is the difference between long-term mortgage rates (15-25 years) and long-term bonds. A logarithm of the gross return on the 15year Czech government bond averaged $4.48 \%$ during the period 2001-2006. For ARM contracts, the premium is the difference between the 1-year adjustable mortgage rate and 1-year PRIBOR. The logarithm of the gross return on PRIBOR averaged $3.43 \%$ during 2000-2006. For mortgage rates we use a simple average of logs of gross rates offered by Czech banks in May 2007. The average rate offered for FRM is $4.81 \%$ and for ARM 3.67\%. These numbers give a calibrated $0.30 \%$ FRM and $0.20 \%$ ARM premium. The ARM premium can be understood as the base mortgage risk. The difference between the FRM and ARM premiums, $0.10 \%$, can be understood as the cost of locking in today's interest rates.

\subsection{Down Payment}

The required down payment with a usual mortgage in the Czech Republic is equal to 20\%, the same number that Campbell and Cocco (2003) calibrated for U.S. households. Additionally, mortgage refinancing usually costs around 20,000 CZK in the Czech Republic.

\subsection{House Size}

We need to compute the cost of an average condominium, as condominiums are the prevailing type of housing in the Czech Republic. We use regional data on real estate prices obtained from Institute for Regional Information in Brno to determine the average per square meter cost of housing. We simply average prices for a standardized 68 square meter older condominium through all the regions of the Czech Republic in 2006. We set the calibrated house size equal to this average, 670,000 CZK. 


\subsection{Inflation}

We estimate the coefficients in the above specified equation for inflation first using monthly data, and then using annual data on Czech CPI for 1994 through 2006. We report the results of estimations using monthly and annual data for three different time intervals, together with values recalculated to annual and bi-annual terms, in Table 5 . The standard deviation of inflation is the standard deviation of the constant coefficient in (3)in a regression based on annual data. In our final version of the calibration, we use estimates in annual terms obtained from annual data for 1994 through 2006. We set mean log inflation to $3.95 \%$ with a standard deviation of $\mu(1-\phi)$ equal to 1.20 . The autoregressive parameter is set to 0.461 .

\subsection{Taxation}

We first compute the average annual labor income over a lifetime for a married head of household with a college education and two children from the above estimation. We then use the Czech Income Tax Act to compute the average tax rate paid by the specified household. This average tax rate is equal to $33 \%$ and we use it to calibrate the simple linear taxation rule in our model.

\subsection{Calibration Overview}

We summarize the calibrated parameters in Table 6 . In addition to that, we report the estimated labor income profile for a married head of household with a college education and two children in Table 7.

\section{Solution Method}

The problem cannot be solved analytically. We use standard numerical techniques for solving it. (Judd 1998). Given the finite nature of the problem a solution exists and can be obtained by backward induction. We start by approximating the state-space and the 
variables over which the choices are made with equally spaced grids. The density functions for the random variables (namely, house prices, both shocks in the labor income process, and interest rates) were approximated using Gaussian quadrature methods to perform numerical integration (Tauchen and Husey 1991). We use a transition probability matrix to approximate the aggregate labor income process.

In period $\mathrm{T}$ and for each admissible combination of the state variables, we obtain the utility associated with each level of terminal wealth. Since this is the terminal period the utility function coincides with the value function. We can use this value function to compute the policy functions for the previous period, and given these, obtain the corresponding value function. This procedure is then iterated backwards. Essentially, the date $t$ value function is equal to current utility plus the expected discounted continuation value associated with the choices made, and given the value of the state variables. To compute this continuation value for points which do not lie on the grid we use cubic spline interpolation. This interpolation has the advantage of being continuously differentiable and having a non-zero third derivative, thus preserving the prudence feature of the utility function. We optimize over the different choices using a standard grid search, to avoid numerical convergence problems and in particular the danger of choosing local optima. We then iterate backwards. Whenever in the solution to the problem the upper limit for the grids turned out to be binding, we increased it and solved the problem again. The support for labor income realizations is bounded away from zero.

To make numerical solution faster, we had to make several simplifying assumptions in the model. Additionally, we set the length of the period in our model as two years in household lifetime. As a result, we had to convert our calibrated parameters to biannual terms. 


\section{Results}

We compare ARM and FRM mortgages first in a benchmark case with calibrated house size 670,000 CZK. We plot histograms of the utility distributions we obtained from 1,000 simulations of the model in Figure 4 for ARM and in Figure 5 for FRM. Next, we compare the distribution of utility over 1,000 simulations at the first and the last percentile, decile, quartile, and at the median in Figure 6. We also report the numerical results in Table 8. We find that for all the reported percentiles, the utility attained under FRM is higher than the utility attained under ARM. We conlude that Czech households are better off under a FRM contract.

This is surprising, because it contradicts our expectations based on the study by Campbell and Cocco (2003). These authors have found that affluent U.S. households are better off under an ARM and others under FRM. In our calibration of the same model for the Czech economy, we do not find such evidence. In contrast, we find that all Czech households are better off under FRM. We hypothesize that this results is due to higher interest rates and inflation uncertainty in the Czech economy compared to the U.S.

Additionally, we run the same 1,000 simulations for a doubled house size, that is, 1,340,000 CZK. The results in Figure 7 show that our results from the benchmark case are robust to the increased house size. That is, Czech households are better off under FRM compared to ARM regardless of the size of the house they wish to buy.

\section{Conclusion}

In the present study, we find that Czech households achieve higher utility if they finance their real estate purchase using a fixed-rate mortgage instead of an adjustable-rate mortgage. Our results differ from the results in Campbell and Cocco (2003), who have found that affluent U.S. households are better off under adjustable-rate mortgage contracts while others are better off under fixed-rate mortgage loans. One can infer from a 
comparison of our and Campbell and Cocco's (2003) results that the optimal choices of mortgage contracts can vary across economies. We hypothesize that this variation stems from differences in real interest rates and inflation volatilities.

Campbell (2006) challenged financial economists to provide research that has clear implications for household finances. Based on our findings, we would recommend Czech households to take FRM loans to finance their housing purchases instead of ARM loans. However, one should be cautious about such implications until further empirical research can confirm these findings. We also think that future research should investigate whether the presented results are robust to the changes in the specification of the real interest rate, house price, and inflation processes. Additionally, further cross-country comparisons might shed more light on why the optimal choice of contract differs across countries. 


\section{References}

Campbell, J.Y., (2006), "Household Finance," Journal of Finance, 61, 1553-1604.

Campbell, J.Y. and Cocco, J.F., (2003), "Household Risk Management and Optimal Mortgage Choice," Quarterly Journal of Economics, 118, 1449-1494.

Campbell, J.Y. and Cocco, J.F., (2002), "Household Risk Management and Optimal Mortgage Choice," Discussion Paper No. 1946, Harvard University.

Carroll, C.D. and Samwick, A.A., (1997), "The Nature of Precautionary Wealth," Journal of Monetary Economics, 40, 41-72.

Case, K.E., Quigley, J.M. and Shiller, R.J., (2001), "Comparing Wealth Effects: The Stock Market Versus the Housing Market," Discussion Paper No. 1335, Cowles Foundation.

Cocco, J.F., (2005), "Portfolio Choice in the Presence of Housing," Review of Financial Studies, 18, $535-567$.

Cocco, J.F., Gomes, F. and Maenhout, P., (2002), "Consumption and Portfolio Choice over the Life Cycle," unpublished paper, London Business School.

Czech Statistical Office, http://www.czso.cz/csu/redakce.nsf/i/rodinne_ucty, Retrieved April 30, 2007.

Flavin, M. and Yamashita, T., (1998), "Owner-occupied Housing and the Composition of the Household Portfolio Over the Life Cycle," Working Paper 6389, U.S. National Bureau of Economic Research.

Gomes, F. and Michaelides, A., (2005), "Optimal Life-Cycle Asset Allocation: Understanding the Empirical Evidence," Journal of Finance, 60, 869-904.

Gourinchas, P.O. and Parker, J.A., (2002), "Consumption Over the Life Cycle," Econometrica, 70, 47-89.

Hrdlička, P., (1998), "Hypoteční úvěr a hypoteční bankovnictví v České republice," Diplomová práce, FSV, Univerzita Karlova.

Judd, K.L., (1998), Numerical Methods in Economics, MIT Press, Cambridge, Massachusetts.

Ortalo-Magne, F. and Rady, S., (2003), "Housing Market Dynamics: On the Contribution of Income Shocks and Credit Constraints," Working Paper, University of Wisconsin-Madison.

Piazzesi, M., Schneider, M. and Tuzel, S., (2007), "Housing, Consumption, and Asset Pricing.," Journal of Financial Economics, 83, 531-569.

Tauchen, G. and Hussey, R., (1991), "Quadrature-based Methods for Obtaining Approximate Solutions to Non-linear Asset Pricing Models," Econometrica, 59, 371-396.

Yao, R. and Zhang, H.H., (2005), "Optimal Consumption and Portfolio Choice with Risky Housing and Borrowing Constraints," Review of Financial Studies, 18, 197-239. 
Table 1: Summary Statistics, 1991-2005

\begin{tabular}{cccccc}
\hline Variable & Obs & Mean & Std. Dev. & Min & Max \\
\hline year & 25366 & 1997.995 & 4.692472 & 1991 & 2005 \\
income & 25366 & $253784 \mathrm{Kc}$ & 146854.9 & $140 \mathrm{Kc}$ & $1953335 \mathrm{Kc}$ \\
age & 25366 & 44.84 & 9.778449 & 20 & 60 \\
members & 25366 & 3.24 & 1.104712 & 1 & 9 \\
married & 25366 & $95.53 \%$ & 0.2066606 & 0 & 1 \\
household composition & 25366 & 1.29 & 1.041755 & -0.5 & 7 \\
high school & 25366 & $81.63 \%$ & 0.3872877 & 0 & 1 \\
college & 25366 & $15.09 \%$ & 0.3579688 & 0 & 1 \\
real income & 23533 & $285487 \mathrm{Kc}$ & 122061.9 & $312 \mathrm{Kc}$ & $1864759 \mathrm{Kc}$ \\
log real income & 23533 & 12.46433 & 0.4742476 & 5.744828 & 14.43864 \\
\hline
\end{tabular}


Table 2: Unbalanced Panel, controlling for education, 1991-2005

\begin{tabular}{ccc}
\hline Variable & \multicolumn{2}{c}{ Coefficient } \\
& (t-Statistic) \\
\hline & 0.078352 & 0.0348975 \\
age30 & $(3.03)$ & $(1.37)$ \\
& 0.1803734 & 0.0963815 \\
age35 & $(6.10)$ & $(3.28)$ \\
& 0.2790055 & 0.1622402 \\
age40 & $(8.89)$ & $(5.18)$ \\
& 0.3088595 & 0.1819157 \\
age45 & $(9.58)$ & $(5.64)$ \\
& 0.331905 & 0.2158073 \\
age50 & $(10.07)$ & $(6.57)$ \\
& 0.3047752 & 0.1772985 \\
age55 & $(9.34)$ & $(5.43)$ \\
& 0.2808802 & 0.1248686 \\
age60 & $(8.60)$ & $(3.79)$ \\
& 0.0515076 & 0.0307786 \\
high school & $(1.61)$ & $(0.98)$ \\
& 0.2009289 & 0.1723535 \\
college & $(5.67)$ & $(4.94)$ \\
& 0.42932 & 0.4149746 \\
married & $(13.17)$ & $(12.94)$ \\
& 0.0580154 & 0.0655003 \\
household composition & $(9.07)$ & $(10.39)$ \\
& 11.65556 & 11.56302 \\
const & $(220.62)$ & $(221.78)$ \\
& & 0.0291515 \\
trend & & $(21.68)$ \\
& &
\end{tabular}


Table 3: Coefficients of the Polynomial Approximating the Log of Real Labor Income Age Profile

\begin{tabular}{ccccccc}
\hline degree & $a g e^{5}$ & $a g e^{4}$ & $a g e^{3}$ & $a g e^{2}$ & age & const \\
\hline 5th & -0.0000000223 & 0.0000055865 & -0.0005341041 & 0.0238888420 & -0.4823738099 & 15.9424091797 \\
4th & & 0.0000011204 & -0.0001856511 & 0.0106578612 & -0.2383159066 & 14.1953504829 \\
3rd & & & -0.0000063886 & 0.0002602391 & 0.0198540304 & 11.8871526411 \\
2rd & & & & -0.0005063980 & 0.0490421405 & 11.5373744685 \\
\hline
\end{tabular}


Table 4: Estimates of Variance of Labor Income Shocks

\begin{tabular}{ccc}
\hline differences & $\sigma_{u}^{2}$ & $\sigma_{\epsilon}^{2}$ \\
\hline 14 & 0.011121 & 0.044438 \\
5 & 0.005142 & 0.044298 \\
2 & 0.007361 & 0.047256 \\
\hline
\end{tabular}


Table 5: Estimated Coefficients of the Inflation Process

\begin{tabular}{cccc}
\hline regression & $\phi$ & $\mu$ & std.err. of $\mu(1-\phi)$ \\
\hline \hline & $1991-2006$ & & 0.0007584 \\
\hline \hline monthly data, monthly terms & 0.2969566 & 0.00525372971284 & \\
monthly data, annual terms & 0.000000470235903586166 & 0.00525372971284 & \\
monthly data, biannual terms & 0.000000000000221121805021498 & 0.00525372971284 & 0.0198217 \\
annual data, annual terms & 0.6054304 & 0.053340247 & 0.0120918 \\
annual data, biannual terms & 0.366545969 & 0.020115358 & \\
\hline \hline & $1994-2006$ & & 0.03948319 \\
\hline annual data, annual terms & 0.4612568 & 0.012463169 & \\
annual data, biannual terms & 0.212757836 & & \\
\hline \hline & $1999-2006$ & 0.0020684540635 & \\
\hline \hline monthly data, monthly terms & 0.0855006 & 0.0020684540635 & \\
monthly data, annual terms & 0.00000000000015262650126314 & 0.0082309 \\
monthly data, biannual terms & 0.000000000000000000000000023 & 0.0020684540635 & \\
annual data, annual terms & -0.0176528 & 0.02506572 & 0.000311621 \\
annual data, biannual terms & -0.000450432 & & \\
\hline
\end{tabular}


Table 6: Calibrated Parameters

\begin{tabular}{ccc}
\hline Parameter & Symbol & Value \\
\hline Risk aversion & $\gamma$ & 3 \\
Discount factor & $\beta$ & 0.98 \\
House size (in thousands of Kč) & $\mathrm{H}$ & 670 \\
Down Payment ratio & $\lambda$ & 0.20 \\
Tax Rate & $\tau$ & 0.33 \\
Mean log inflation & $\mu$ & 0.039 \\
Standard deviation of log inflation & $\sigma\left(\pi_{1 t}\right)$ & 0.012 \\
Inflation autoregression parameter & $\phi$ & 0.461 \\
Mean log real yield & $\bar{r}$ & 0.037 \\
Standard deviation of real log yield & $\sigma\left(r_{1 t}\right)$ & 0.013 \\
FRM premium & $\theta^{F}$ & 0.003 \\
ARM premium & $\theta^{A}$ & 0.002 \\
Mean net real house price growth & $\mathrm{g}$ & 0.106 \\
Standard deviation of real house price growth & $\sigma_{\delta}$ & 0.060 \\
Standard deviation of transitory income shocks & $\sigma_{\epsilon}$ & 0.044 \\
Standard deviation of persistent income shocks & $\sigma_{u}$ & 0.005 \\
Refinancing cost (in thousands of Kč) & $\mathrm{rf}$ & 1.000 \\
\hline
\end{tabular}


Table 7: Labor Income Profile

\begin{tabular}{|c|c|}
\hline Age Bracket & Annual Labor Income for a Married Head of Household with a College Education and Two Children \\
\hline $20-25$ & $243,252 \mathrm{Kc \check {c }}$ \\
\hline $25-30$ & $263,076 \mathrm{Kč}$ \\
\hline $30-35$ & $291,336 \mathrm{Kč}$ \\
\hline $35-40$ & $321,528 \mathrm{Kč}$ \\
\hline $40-45$ & $331,272 \mathrm{Kc \check {c }}$ \\
\hline $45-50$ & $339,000 \mathrm{Kc \check {c }}$ \\
\hline $50-55$ & 329,928 Kč \\
\hline $55-60$ & $322,128 \mathrm{Kc \check {c }}$ \\
\hline
\end{tabular}


Table 8: Simulation Results

\begin{tabular}{cccccccc}
\hline Setup & $1 \%$ & $10 \%$ & $25 \%$ & $50 \%$ & $75 \%$ & $90 \%$ & $99 \%$ \\
\hline ARM, house $=67$ & -0.0308 & -0.0283 & -0.0268 & -0.0252 & -0.0237 & -0.0226 & -0.0209 \\
FRM, house=67, refcost=2 & -0.0234 & -0.0224 & -0.0218 & -0.0211 & -0.0204 & -0.0199 & -0.0191 \\
ARM, house $=134$ & -0.0653 & -0.0567 & -0.0524 & -0.0486 & -0.0451 & -0.0427 & -0.0387 \\
FRM, house=134, refcost=2 & -0.0414 & -0.0389 & -0.0376 & -0.0361 & -0.0348 & -0.0336 & -0.0322 \\
\hline
\end{tabular}


Figure 1: Labor Income - Age Profile

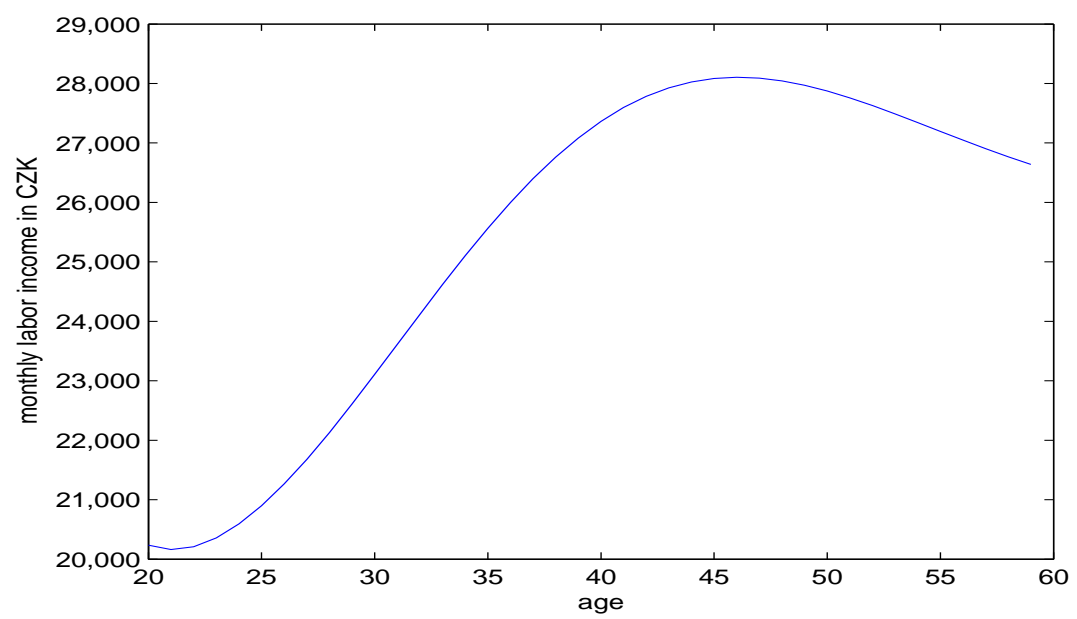


Figure 2: Labor Income - Age Profile with Simulated 95 \% Confidence Intervals

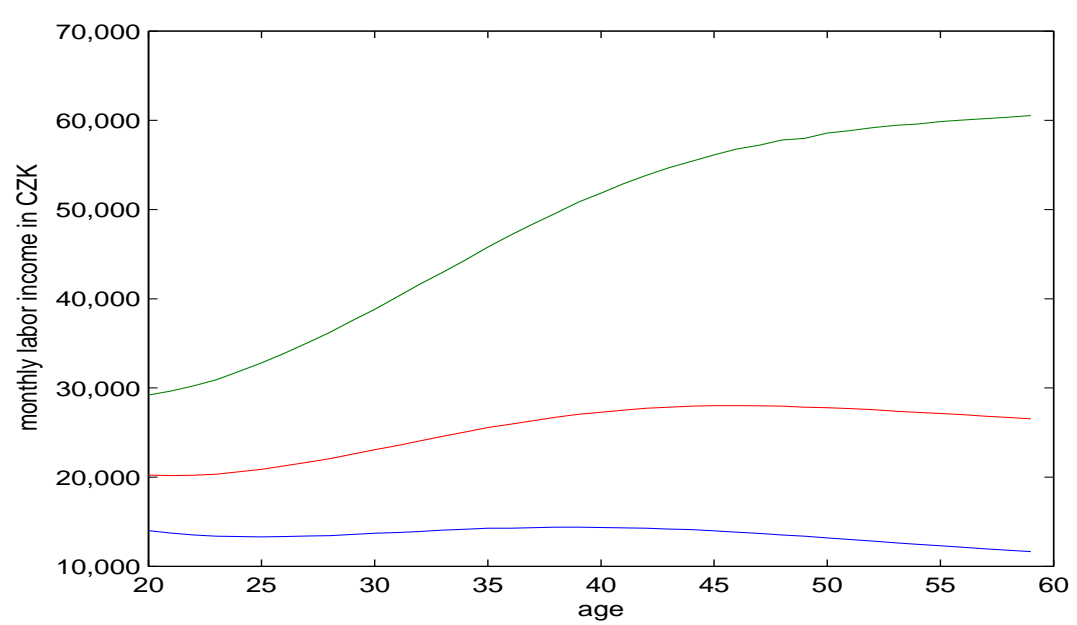


Figure 3: Labor Income - Age Profile with Simulated Approximated $95 \%$ Confidence Intervals

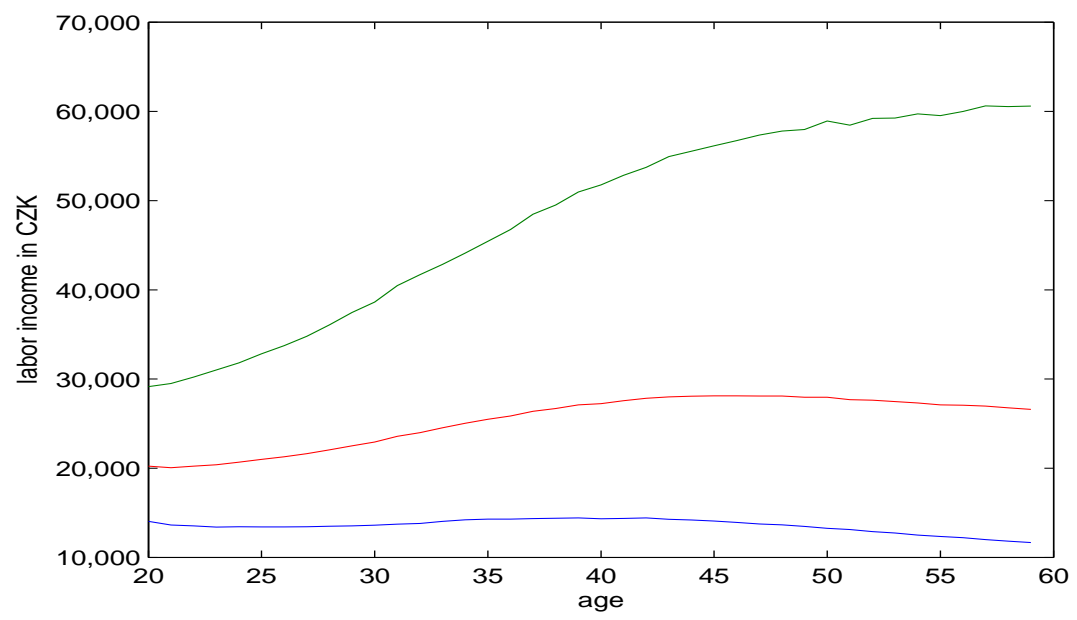


Figure 4: Distribution of Utility under ARM

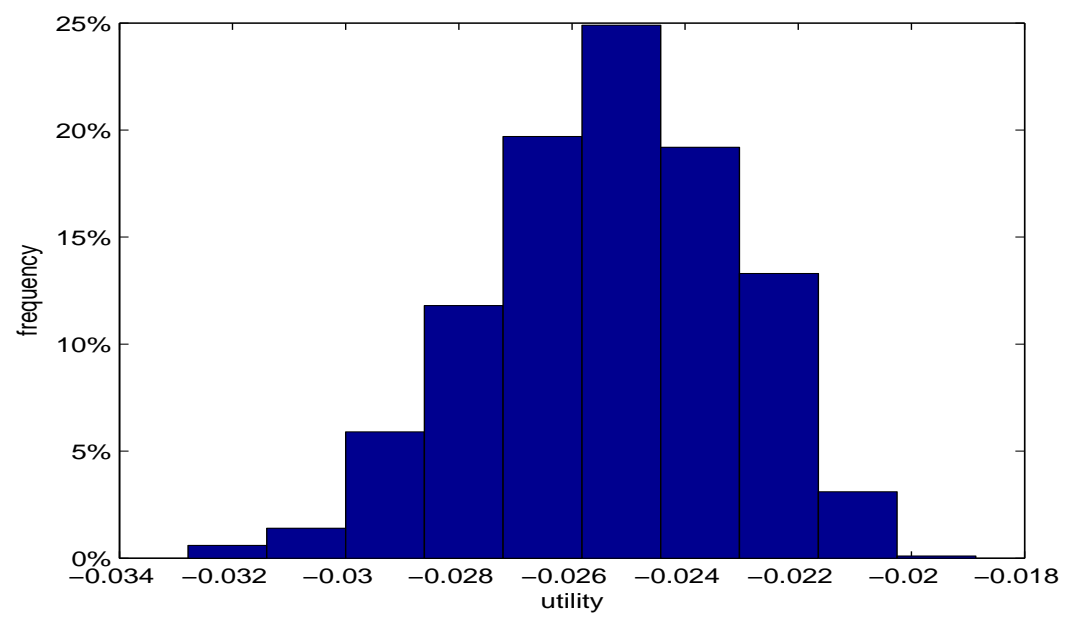


Figure 5: Distribution of Utility under FRM

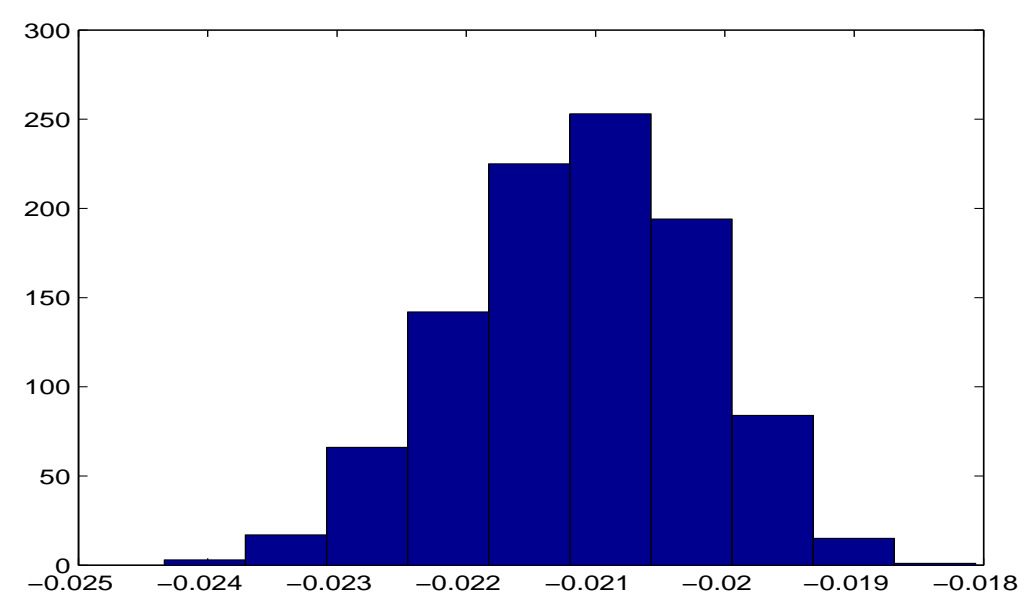


Figure 6: Utility under ARM and FRM: Benchmark Case

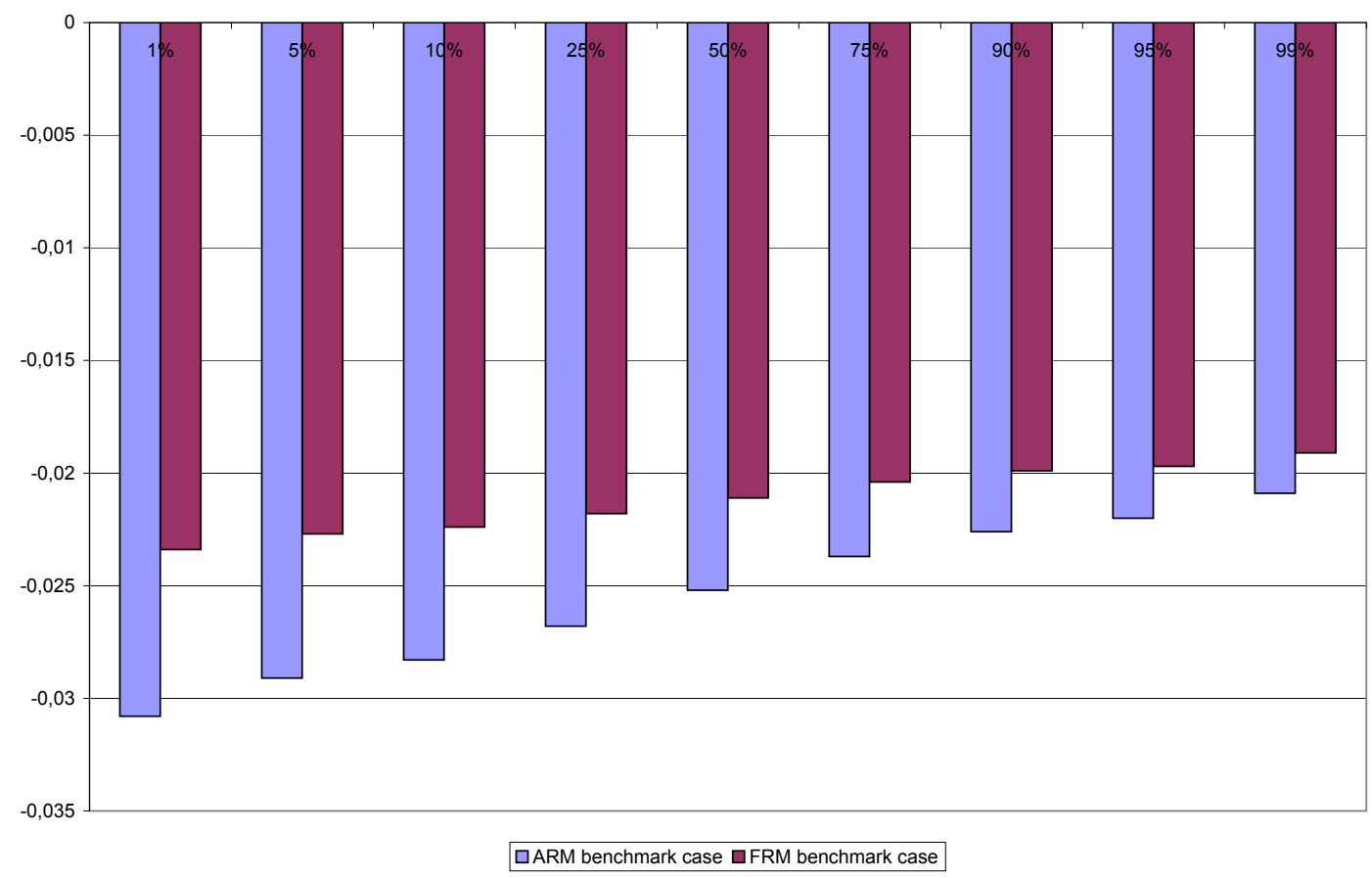


Figure 7: Utility under ARM and FRM: Double House Size

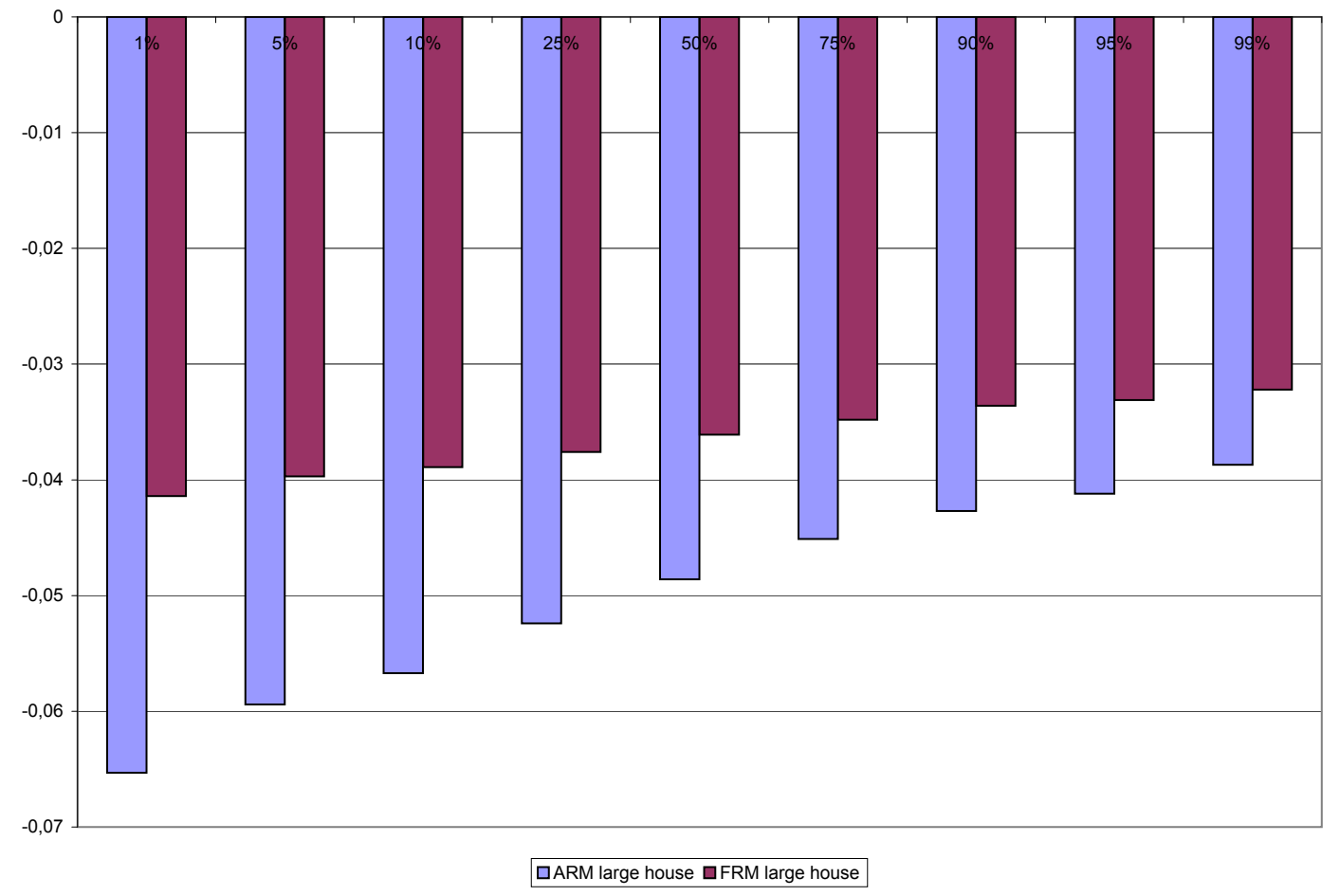

